\title{
A Rare Case of Spontaneous Resolution of Eosinophilic Ascites in A Patient with Primary Eosinophilic Gastroenteritis
}

\author{
Wei-Hsuan Liao, MD; Kuo-Liang Wei, MD; Po-Yen-Lin¹, MD; Cheng-Shyong Wu, MD
}

Eosinophilic gastroenteritis is a rare gastrointestinal disorder characterized by nonspecific gastrointestinal symptoms, peripheral eosinophilia, and eosinophilic infiltration of the intestinal wall. The disorder is classified into mucosal, muscular, and subserosal types, depending on the depth of eosinophilic infiltration within the gastrointestinal wall, and the clinical picture varies accordingly. Subserosal disease, which is complicated by ascites, usually results in the most severe clinical form of eosinophilic gastroenteritis and mandates early corticosteroid therapy. In such cases, a favorable outcome can be achieved after a short course of corticosteroids. We present a rare case in a 43 year-old man in whom eosinophilic gastroenteritis spontaneously resolved without any medical treatment. After reviewing the literature and excluding secondary causes of eosinophilic gastroenteritis, we concluded that this may be the first reported case of spontaneous resolution of primary subserosal eosinophilic gastroenteritis. (Chang Gung Med J 2012;35:354-9)

Key words: eosinophilic gastroenteritis, eosinophilic ascites, subserosal disease

$\mathrm{E}_{\mathrm{c}}^{\mathrm{o}}$ osinophilic gastroenteritis (EG) is a rare disease characterized by abdominal discomfort and intense eosinophilic infiltration of the gastrointestinal tract found on histology. Because the symptoms of EG are usually nonspecific abdominal pain and its clinical course is chronic with remission and relapse, it is often misdiagnosed as functional bowel disease. In addition, because of its low incidence rate (approximately $1 / 100,000),{ }^{(1)}$ physicians seldom think of this rare disease entity.

According to Klein's classification system, the symptomatology differs between the mucosal, muscular, and subserosal forms of EG. ${ }^{(2)}$

This article reports a rare case of simultaneous mucosal and subserosal forms of EG, which typically presents with significant bloating, intense peripheral eosinophilia, and eosinophilic ascites. ${ }^{(3,4)}$

The treatment of choice for EG is a short course of corticosteroids although there are several other promising medications with limited therapeutic histories. Among the 3 types of EG, the clinical course of the subserosal form is the worst. Patients with subserosal disease always need early treatment with corticosteroids. Favorable outcomes can usually be expected. ${ }^{(4)}$

Here, we present a case of spontaneous resolution of eosinophilic ascites in EG without steroid treatment, which has rarely been reported.

\section{CASE REPORT}

\section{Initial presentation and history}

A 43-year-old Taiwanese man, who was a marathon runner had severe and intermittent crampy epigastralgia for 2 months. He had a history of intermittent, moderate epigastralgia about once a year over the past several years, but his condition had not been definitely diagnosed. There was no increased

From the Division of Gastroenterology, Department of Internal Medicine; 'Department of Pathology, Chang Gung Memorial Hospital at Chiayi Chang Gung University College of Medicine, Taoyuan, Taiwan.

Received: Jan. 6, 2011; Accepted: Feb. 10, 2012

Correspondence to: Dr. Kuo-Liang Wei, Division of Gastroenterology, Department of Internal Medicine, Chang Gung Memorial Hospital at Chiayi, Taiwan. 6, W. Sec., Jiapu Rd., Puzih City, Chiayi County 613, Taiwan (R.O.C.) Tel: 886-5-3821000 ext. 2005; Fax: 886-5-3623005; E-mail: wkliang@cgmh.org.tw 
flatus or nausea but he had frequent, small amounts of soft stool concomitant with abdominal pain. There was no obvious aggravating or relieving factors for his abdominal pain. In the previous 3 weeks, he had a poor appetite and progressive abdominal fullness. $\mathrm{He}$ had lost $6 \mathrm{~kg}$ of body weight in approximately 20 days. He went to a local clinic where an abdominal echo revealed a massive amount of ascites. The patient came to our gastrointestinal department for further examination.

The patient had no history of allergic rhinitis, asthma, food allergy, atopic dermatitis, or any other systemic disease. None of his family members had similar abdominal symptoms recently. His father died of colon cancer.

\section{Physical examination}

On admission, his body temperature was $36.2^{\circ} \mathrm{C}$; blood pressure, $128 / 89 \mathrm{mmHg}$; respiratory rate, 18/min; heart rate, $64 \mathrm{bpm}$; height, $170 \mathrm{~cm}$; and body weight, $63 \mathrm{~kg}$ (down from a previously constant $69 \mathrm{~kg}, 3$ weeks ago). His physical examination showed moderate abdominal distention. Ascites was suspected as shifting dullness was noted in the abdomen. He did not feel abdominal tenderness under deep palpation. There were no other significant abnormalities.

\section{Laboratory and imaging studies}

The routine hemogram data were as follows: 11,000 white blood cells (WBCs) $/ \mu \mathrm{L}$; segments, $32 \%$; lymphocytes, $12 \%$; monocytes, $6 \%$; eosinophils, 49\%; and basophils, 1\%. The absolute eosinophil count was $5390 / \mu \mathrm{L}$. The biochemistry data were as follows: creatinine, $1.06 \mathrm{mg} / \mathrm{dL}$; sodium, $139 \mathrm{meq} / \mathrm{L}$; potassium, $3.85 \mathrm{meq} / \mathrm{dL}$; alanine aminotransferase, $24 \mathrm{U} / \mathrm{L}$; albumin, $3.7 \mathrm{~g} / \mathrm{dL}$; and Creactive protein, $<5 \mathrm{mg} / \mathrm{L}$. Peripheral hypereosinophilia was documented. The patient had not taken any medication or consumed contaminated water or raw food recently.

Abdominal ultrasonography (Fig. 1) and computed tomography (Fig. 2) disclosed massive ascites and colon wall thickening. A peritoneal paracentesis was performed and the suctioned ascites was turbid and orange. Routine analysis of the ascites revealed the following: WBCs, $1700 / \mu \mathrm{L}$; red blood cells, $10,000 / \mu \mathrm{L}$; neutrophils, $0 \%$; lymphocytes, $1 \%$; and eosinophils, $99 \%$. The absolute eosinophil count was

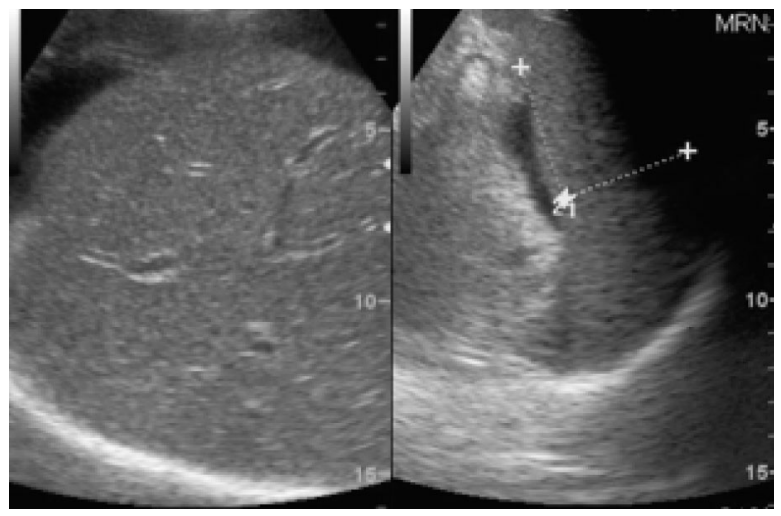

Fig. 1 Abdominal ultrasonography at admission shows moderate ascites (arrows).

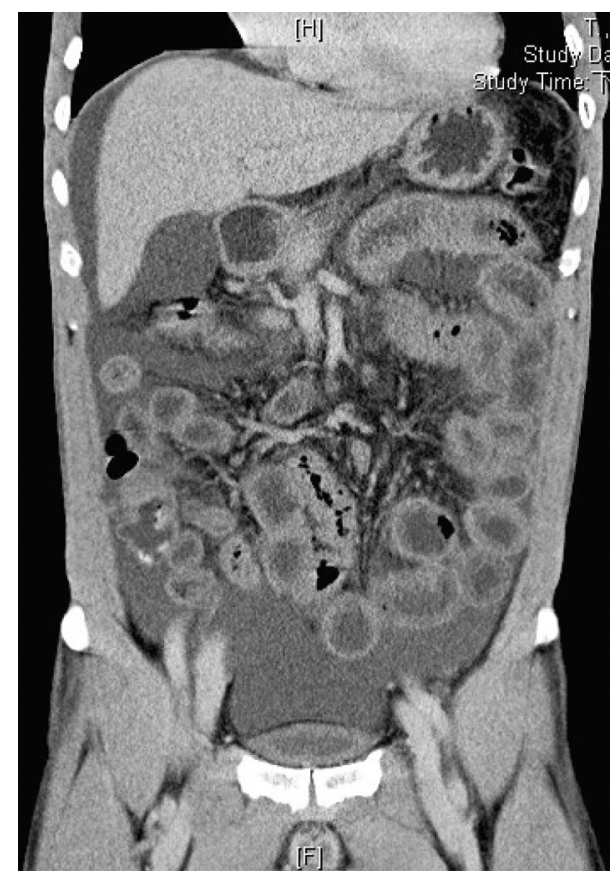

Fig. 2 Computed tomography at admission shows colon wall edematous changes and moderate ascites.

$1683 / \mathrm{uL}$. The total protein and albumin in the ascites were $6.2 \mathrm{~g} / \mathrm{dL}$ and $3.6 \mathrm{~g} / \mathrm{dL}$, respectively (serumascites albumin gradient: 0.1 ). There were no malignant cells on cytological examination of the ascites. The gram stain and culture of the ascites were negative. Stool collected for routine analysis and culture was negative for pus, mucus, parasites and ova, but the fecal occult blood test result was $2+$. The urinalysis was normal without proteinuria or hematuria. 
The serum $\operatorname{IgE}(364 \mathrm{IU} / \mathrm{mL})$ was elevated and $\operatorname{IgG}, \operatorname{Ig} \mathrm{A}$, and $\operatorname{IgM}$ levels were within the normal ranges. Serum C3 (110 mg/dL) and C4 $(37.2 \mathrm{mg} / \mathrm{dL})$ levels were normal, but elevated anti-double-stranded-DNA antibody $(160.79 \mathrm{IU} / \mathrm{mL})$ was noted. A hematologist was consulted and a bone-marrow examination was recommended; however, the patient refused to undergo an invasive examination. A rheumatologist performed a skin-prick test (SPT) and radioallergosorbent test (RAST) which showed no abnormalities.

\section{Diagnosis and management}

A panendoscopy showed the esophagus and duodenum were normal, but mild erythematous gastritis was noted. Randomized biopsies were performed at the esophagogastric junction, stomach, and duodenal bulb. The pathology report noted gastric erosions, and acute and chronic inflammation in the esophagus and the duodenal bulb. Helicobacter pylori were not seen in the specimen. A colonoscopy showed erythematous patches in the cecum and transverse colon, and target biopsies were performed. The final pathology report was compatible with colitis with mild eosinophilic infiltration of the colonic mucosa (Fig. 3). A diagnosis of simultaneous mucosal and subserosal EG was made.

The patient's abdominal pain and soft-stool diarrhea were partially relieved before admission and the symptoms did not recur during hospitalization. Therefore, no medication was prescribed. An abdom-

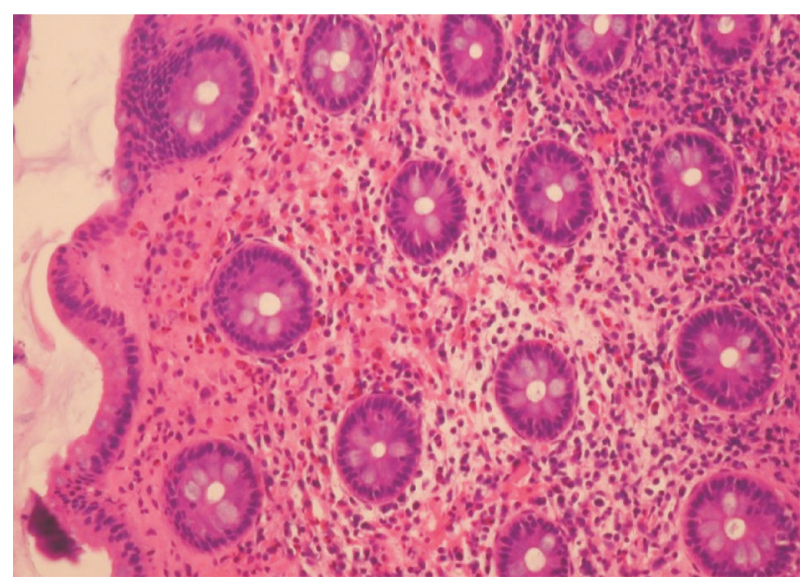

Fig. 3 Cecum mucosal tissue with an increase in eosinophilic infiltration in the lamina propria (Hematoxylin and eosin stains, $\mathrm{x} 100$ ) inal echo one week later (Fig. 4) surprisingly documented complete resolution of his moderate ascites. The patient was discharged after 10 days and there was no relapse thereafter.

\section{DISCUSSION}

EG is rare in adults. The diagnosis of EG is based on the following 3 criteria: (1) gastrointestinal symptoms, (2) eosinophilic infiltration of 1 or more areas of the gastrointestinal tract, and (3) exclusion of other causes of intestinal eosinophilia. ${ }^{(5)}$

The range of clinical presentations of EG differs widely with the location and depth of eosinophilic inflammation in the intestinal wall. According to Klein's classification, the symptomatology is classified as mucosal, muscular, or subserosal. ${ }^{(2)}$

EG patients with subserosal involvement typically have eosinophilic ascites, high levels of peripheral eosinophilia, and severe bloating. ${ }^{(4,6)}$ Some studies recommend laparoscopy in suspected cases of subserosal EG to differentiate EG from other etiologies of peritoneal inflammatory disease. The main findings of subserosal EG on laparoscopy are ascites, white nodules, and thickening of both the parietal and visceral peritoneum. Further full-layer surgical biopsy during laparoscopy may be required. ${ }^{(7)}$

Our patient was a 43-year-old man. EG predominantly affects men at around the third to fourth decade of life, but it can also affect patients of other ages. ${ }^{(1)}$ This patient had recurrent episodes of epigastralgia several times in previous years. Previously, repeated panendoscopy and colonoscopy revealed only shallow peptic ulcers. His previous diagnosis

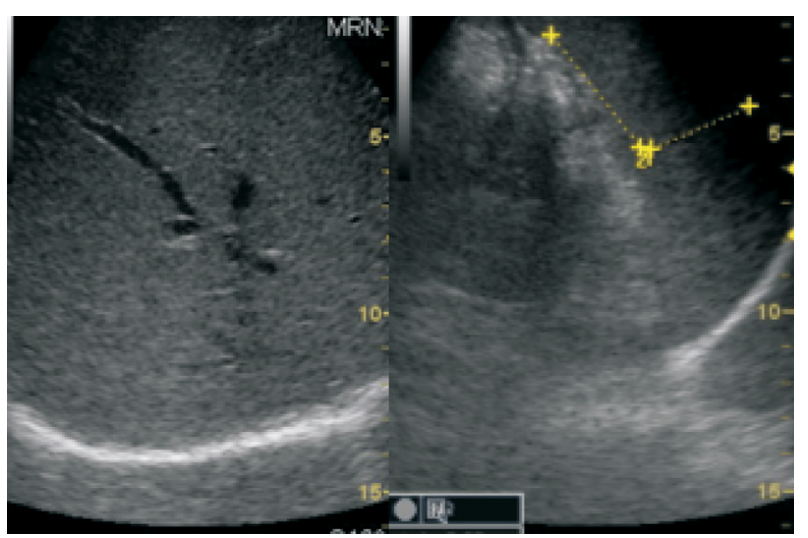

Fig. 4 Resolution of ascites at discharge 
was irritable bowel syndrome and the symptoms were refractory to medication. His present routine hemogram data revealed peripheral hypereosinophilia $(11,000 \mathrm{WBCs} / \mu \mathrm{L}$; eosinophils, $49 \%$; absolute eosinophil count, 5390/ $\mu \mathrm{L}$ ), which had not been noted previously at other hospitals. Patients with predominantly subserosal EG have higher absolute peripheral eosinophil counts (average 8000/uL) than patients with mucosal disease (average 2000/uL) and muscle-layer involvement (average 1000/uL). ${ }^{(8)}$ Peripheral eosinophilia is noted in $50-100 \%$ of patients with EG, but it is not a prerequisite for diagnosis. ${ }^{(6)}$

The abdominal echo disclosed moderate ascites, which was unexpected in a healthy young man without heart, liver, or kidney disease. Paracentesis of the ascites found intense eosinophil infiltration (1700 WBCs $/ \mu \mathrm{L}$; eosinophils, 99\%). On the basis of the abovementioned findings, subserosal EG was highly suspected. Panendoscopy and colonoscopy with tissue biopsy were done because of suspected eosinophilic infiltration in the mucosal layer of the gastrointestinal tract.

Only mild erythematous gastritis was found with no abnormalities in the esophagus and duodenum. Randomized biopsies were performed at the levels of the esophagogastric junction, stomach, and duodenal bulb. Multiple randomized biopsies of apparently normal mucosa were needed because patchy disease has been reported and the diagnosis could easily be missed. Therefore, more than 1 endoscopic biopsy is recommended. ${ }^{(9)}$ Pathological examination excluded $\mathrm{H}$. pylori infection, which rarely causes focal eosinophilic infiltration. ${ }^{(6)}$ On colonoscopy, patches of erythematous mucosa were noted in the cecum and transverse colon; and thus, target biopsies were performed. Weak eosinophilic infiltration in the colonic mucosa was documented. Simultaneously, involvement of mucosal and subserosal EG was confirmed.

The etiology of EG could be primary or secondary. EG occurs secondarily to inflammatory bowel disease, autoimmune diseases, reactions to medications, infections, hypereosinophilic syndrome, and solid-organ transplantation. Among the secondary causes of EG, an atopic history and allergies are present in $25-75 \%$ of patients. ${ }^{(10)}$ Our patient had no history of reactions to medications, allergies, asthma, or rheumatologic disease. The SPT and
RAST were both negative. The colonic mucosal biopsy, routine stool examination, and cultures were negative for gastrointestinal infections, including parasites. From the above findings, a diagnosis of primary EG with simultaneous mucosal and subserosal involvement was made.

In comparison with other forms of EG, the clinical symptoms of subserosal disease are generally more severe, which mandates early steroid therapy. Fortunately, the general prognosis is good and the response to steroids is usually favorable. Most patients with subserosal disease recover after a short course of corticosteroids (Durieu's study cites a 90\% positive response). ${ }^{(1)}$ The recommended dose of steroids is $1-2 \mathrm{mg} / \mathrm{kg}$ per day orally for 8 weeks, which is tapered over 6-8 weeks to induce remission. ${ }^{(6)}$ Relapses are usually encountered and repeated doses of steroids or even long-term, low-dose, steroid maintenance therapy could be required. However, long-term steroid therapy results in some side effects, including fluid and electrolyte disturbances, hyperglycemia, a cushingoid state, growth suppression, bone demineralization, pituitary and adrenocortical hyporesponsiveness, and posterior subcapsular cataracts. Steroid-sparing therapy should be considered in refractory cases. ${ }^{(12)}$ Alternative medications, including mast-cell inhibitors, antihistamines, leukotriene-receptor antagonists, and antiinterleukin-5 (mepolizumab) seem promising although clinical experience with these treatments is limited. ${ }^{(6)}$

The patient presented here recovered on the fourth hospital day, and his ascites disappeared spontaneously without any medical treatment. The spontaneous resolution of subserosal EG without steroid treatment in this case contradicts current beliefs with regard to EG, especially primary EG. In a review of 76 case reports from 1990 to date, using "eosinophilic gastroenteritis ascites" as the key word and excluding cases of secondary EG and patients younger than 18 years, only 4 patients were reported to have recovered without medical therapy. ${ }^{(13-16)}$ Two of the four patients had allergic disorders and their clinical symptoms resolved with a food-elimination diet or conservative treatment. ${ }^{(13,14)}$ It is well documented that removal of allergens from the diet improves $90-98 \%$ of patients' symptoms. ${ }^{(17,18)}$ Only short English abstracts could be obtained for the other 2 spontaneously resolved cases and it could not 
be determined whether these patients had histories of allergic disorders or other secondary causes of EG. ${ }^{(15,16)}$ To the best of our knowledge, this is a rare case of primary EG which resolved spontaneously.

\section{Conclusion}

This article presents an uncommon case of simultaneous mucosal and subserosal EG. Corticosteroids are the mainstay therapy for EG, especially for primary EG. Observation of spontaneous resolution in this case provides a new viewpoint with regard to the natural course and management of primary EG. To our knowledge, this case may be the first well-documented case of spontaneous resolution of primary EG.

\section{REFERENCES}

1. Mueller S. Classification of eosinophilic gastrointestinal diseases. Best Pract Res Clin Gastroenterol 2008;22:42540.

2. Klein NC, Hargrove RL, Sleisenger MH, Jeffries GH. Eosinophilic gastroenteritis. Medicine (Baltimore) 1970;49:299-319.

3. Talley NJ, Shorter RG, Phillips SF, Zinsmeister AR. Eosinophilic gastroenteritis: a clinicopathological study of patients with disease of the mucosa, muscle layer, and subserosal tissues. Gut 1990;31:54-8.

4. Chen MJ, Chu CH, Lin SC, Shih SC, Wang TE. Eosinophilic gastroenteritis: clinical experience with 15 patients. World J Gastroenterol 2003;9:2813-6.

5. Cello JP. Eosinophilic gastroenteritis-a complex disease entity. Am J Med 1979;67:1097-104.

6. Khan S. Eosinophilic gastroenteritis. Best Pract Res Clin
Gastroenterol 2005;19:177-98.

7. Solis-Herruzo JA, De Cuenca B, Muñoz-Yagüe MT. Laparoscopic findings in serosal eosinophilic gastroenteritis. Report of two cases. Endoscopy 1988;20:152-3.

8. Naylor AR. Eosinophilic gastroenteritis. Scott Med J 1990;35:163-5.

9. Velchuru VR, Khan MA, Hellquist HB, Studley JG. Eosinophilic Colitis. J Gastrointest Surg 2007;11:1373-5.

10. Khan S, Orenstein SR. Eosinophilic gastroenteritis: Epidemiology, diagnosis and management. Paediatr Drugs 2002;4:563-70.

11. Durieu I, Nove-Josserand R, Cathebras P, vital Durand P, Rousset H, Levrant R. Eosinophilic ascites. 2 new case reports. Rev Med Interne 1992;13:446-8 (article in French).

12. Yan BM, Shaffer EA. Primary eosinophilic disorders of the gastrointestinal tract. Gut 2009;58:721-32.

13. Miyamoto T, Shibata T, Matsuura S, Kagesawa M, Ishizawa Y, Tamiya K. Eosinophilic gastroenteritis with ileus and ascites. Intern Med 1996;35:779-82.

14. Pfaffenbach B, Adamek RJ, Bethke B, Stolte M, Wegener M. Eosinophilic gastroenteritis in food allergy. Z Gastroenterol 1996;34:490-3 (Article in German).

15. Geraghty JG, McCabe MC, Murphy JJ, O’Higgins NJ. Eosinophilic gastroenteritis presenting as ascites. Case report. Eur J Surg 1992;158:63-4.

16. Yassin MA, Khan FY, Al-Ani A, Fawzy Z, Al-Bozom IA. Ascites and eosinophilic colitis in a young patient. Saudi Med J 2005;26:1983-5.

17. Liacouras CA, Spergel JM, Ruchelli E. Eosinophilic esophagitis: a 10-year experience in 381 children. Clin Gastroenterol Hepatol 2005;3:1198-206.

18. Spergel JM, Andrews T, Brown-Whitehorn TF, Beausoleil JL, Liacouras CA. Treatment of eosinophilic esophagitis with specific food elimination diet directed by a combination of skin prick and patch tests. Ann Allergy Asthma Immunol 2005;95:336-43. 


\title{
自動消失的嗜伊紅性腹水：原發性㖺伊紅性腸胃炎罕見的表現
}

\author{
廖威宣 魏國良 林博彦 ${ }^{1}$ 吴正雄
}

\begin{abstract}
嗜伊紅性腸胃炎的特色是週邊血液有高嗜伊紅性球, 腸胃道組織有嗜伊紅性球浸潤及配 合臨床上不具專一性的症狀。其臨床表現和嗜伊紅性球浸犯組織的深度相關, 可分爲秥膜 層, 肌肉層以及漿膜層内。嗜伊紅性球若侵入漿膜層之下時, 常會併發腹水, 這是嗜伊紅性 腸胃炎中最嚴重的症狀之一, 需要及早的類固醇治療, 通常短期的類固醇治療效果不錯。本 病例特別處在於病人在沒有經過治療, 其腹水即自動消失。本病例已排除次發性嗜伊紅性腸 胃炎, 經文獻查詢, 這可能是原發性嗜伊紅性腸胃炎併腹水的病例, 首次不需類固醇治療而 恢復的。(長庚醫誌 2012;35:354-9)
\end{abstract}

關鍵詞：嗜伊紅性腸胃炎, 嗜伊紅性腹水, 漿膜層下病變

長庚醫療財團法人嘉義長庚紀念醫院 內科部 肝膽胃腸科，1病理科；長庚大學 醫學院 受文日期：民國100年1月6日；接受刊載：民國101年2月10日

通訊作者: 魏國良醫師, 長庚醫療財團法人嘉義長庚紀念醫院 內科部 肝膽胃腸科。嘉義縣613朴子市嘉朴路西段6號。 Tel: (05)3821000轉2005; Fax: (05)3623005; E-mail: wkliang@cgmh.org.tw 